\title{
Non-enzymatic browning and flavour kinetics of vacuum dried onion slices
}

\author{
Jayeeta Mitra*, Shanker L. Shrivastava, and Pavuluri S. Rao \\ Department of Agricultural and Food Engineering, Indian Institute of Technology, Kharagpur-721302, India
}

Received March 19, 2014; accepted November 27, 2014

\begin{abstract}
A b s t r a c t. Onion slices were dehydrated under vacuum to produce good quality dried ready-to-use onion slices. Colour development due to non-enzymatic browning and flavour loss in terms of thiosulphinate concentration was determined, along with moisture content and rehydration ratio. Kinetics of non-enzymatic browning and thiosulphinate loss during drying was analysed. Colour change due to non-enzymatic browning was found to be much lower in the case of vacuum dried onion, and improved flavour retention was observed as compared to hot air dried onion slices. The optical index values for non-enzymatic browning varied from 18.41 to 38.68 for untreated onion slices and from 16.73 to 36.51 for treated slices, whereas thiosulphinate concentration in the case of untreated onion slices was within the range of 2.96-3.92 $\mu \mathrm{mol} \mathrm{g} \mathrm{g}^{-1}$ for dried sample and 3.71-4.43 $\mu \mathrm{mol} \mathrm{g}{ }^{-1}$ for the treated onion slices. Rehydration ratio was also increased, which may be attributed to a better porous structure attained due to vacuum drying. The treatment applied was found very suitable in controlling non-enzymatic browning and flavour loss during drying, besides increasing rehydration ratio. Hence, high quality dried ready- to-use onion slices were prepared.

$\mathrm{K}$ e y w o r d s: vacuum drying, non-enzymatic browning, flavour kinetics, rehydration ratio
\end{abstract}

\section{INTRODUCTION}

Onion (Allium cepa) is a vegetable providing numerous health benefits, which makes it very important among the consumers day by day (Lanzotti, 2006). It is the oldest herb cultivated and used mainly in the tropical countries. Dehydrated onions in the form of flakes or powder are in extensive demand in several parts of the world (Sarsavadia et al., 1999). They are widely used in the formulation of meat products, gravies, canned foods, sausage and seasonings, soups, dry soup mixes, cheeses, crackers and other snacks and special food products (Prasad, 1994).

*Corresponding author e-mail: jayeeta_12@yahoo.co.in
The acceptability of dehydrated vegetables depends on the quality attributes of dried samples such as colour, flavour, moisture content and rehydration ratio. Moisture content of a product is important for inducing microbial spoilage and, hence, affects the shelf life of dehydrated product. Besides, the activities of enzymes and vitamins in foods are also governed by water activity which influences the colour, taste, and aroma of food materials. Temperature and $\mathrm{pH}$, along with several other factors, can influence the occurrence of organisms in a product and their growth rate. Moisture content also strongly influences the colour of the product by affecting non-enzymatic browning (NEB) of the product (Driscoll and Madamba, 1994; Legault, 1954; Peleg, 1970; Samaniego-Esguerra, 1991). Researchers pointed out that NEB is virtually zero when the product is at mono-layer moisture content, however, the rate of NEB becomes enhanced at higher water activity (Legault, 1954). An exponential relationship between the browning rate and moisture content is reported, and it is specified that the water activity of $0.6-0.7$ is the most vulnerable range to promote browning in the case of dehydrated onion (Rapusas and Driscoll, 1995).

NEB occurs due to the interaction of aldehyde and ketone group of reducing sugars with amino acids and proteins (Proudlove, 1989). It is further enhanced by temperature during the drying process, resulting in unacceptable colour change, off-flavour development and loss of protein biological value (Aguilera, 1975; Krokida and Maroulis, 1999; Ibarz et al., 2000). The NEB reaction, determined by optical index and loss of pungency denoted in terms of pyruvate or thiosulphinate concentration (TC), are interpreted as the most important factors in determining

(C) 2015 Institute of Agrophysics, Polish Academy of Sciences 
quality degradation of dried onion (Prezzutti and Crapiste, 1997; Schwimmer, 1981). Temperature and moisture content of food during the dehydration process are the main factors to affect the rate of NEB reaction (Hendel, 1955; Labuza and Saltmarch, 1981; Saguey and Karel, 1980).

Onion has a characteristic flavour or aroma due to the presence of volatile substances comprised of sulphur compounds. In intact tissue, these compounds do not react, but upon disintegration of onion tissue, two molecules of flavour precursor ( $S$-alkyl-L-cysteine sulphoxide) undergo hydrolysis and produce two molecules of pyruvate and one molecule of thiosulphinate in the presence of alliinase enzyme (Mazza and LeMaguer, 1980; Schwimmer and Weston, 1961). During dehydration, temperature and time of drying strongly influence the flavour concentration in onion tissues (Da-Mota and Palau, 1999; Prezzutti and Crapiste, 1997).

Researchers have tried to analyse the quality parameters of dried onion for various drying mechanisms and modelled their dependence on drying conditions, though most of them were conventional hot air drying (Cohen and Saguy, 1985; Labuza, 1973; Lenz and Lund, 1980).

Researchers have found that some chemical components of onions are not affected by drying, viz., ash, fat, protein and fibre, whereas some others are considerably influenced by drying, viz., sugars, acidity and vitamin C (Mota et al., 2010). An interesting study was done on irradiation of welsh onion and it was reported that the application of high-dose irradiation required for microbial decontamination of dried Welsh onion enhanced the total concentration of volatile compounds by 31.60 and $24.85 \%$ at 10 and $20 \mathrm{kGy}$, respectively (Gyawali et al., 2006). Sun, oven $\left(50\right.$ and $\left.70^{\circ} \mathrm{C}\right)$, and microwave oven $(210$ and $700 \mathrm{~W})$ drying of onion slices was carried out to monitor the drying kinetics and quality degradation of the product (Arslan and Özcan, 2010). The highest mineral values (calcium, sodium, potassium and magnesium) were determined in oven dried samples. Sun and microwave oven drying $(210 \mathrm{~W})$ revealed better colour values in the dried products. The phenolic contents of microwave oven dried samples were higher than those of the other dried onion slices. Onion slices were dried under infrared radiation assisted by hot air to assess the effect of drying temperature, slice thickness, inlet air temperature and air velocity, and thin layer drying models were developed (Kumar et al., 2006).

The kinetics of colour and flavour concentration during drying has been an important area of research (KaymakErtekin and Gedik, 2005; Rapusas and Driscoll, 1995). The NEB reaction kinetics was reported to be of the zero order (Driscoll and Madamba, 1994; Kaymak-Ertekin and Gedik, 2005; Rapusas and Driscoll, 1995). A relation was further derived between browning and flavour loss kinetics with drying temperature, time and water activity (KaymakErtekin and Gedik, 2005). Flavour change followed second order kinetics, however, the flavour change in terms of pyruvic acid in the case of drying of garlic and during storage of onion as thiosulphinate loss followed a first order reaction (Samaniego-Esguerra et al., 1991; Prezzutti and Crapiste, 1997). Rehydration ratio is also strongly affected by drying temperature and thickness of slice (Vega-Gálvez et al., 2008; Wang and Chao, 2003).

In the present study, vacuum drying was used to dehydrate sliced onions. In vacuum environment, food product can be dried at a relatively lower temperature level, which is essential for heat sensitive products (Copley, 1956; Jena and Das, 2007; Pap, 1995; Péré and Rodier, 2002). Better product quality such as colour, flavour, taste and rehydration ratio can be obtained using high degree vacuum treatment (Drouzas and Schubert, 1996). The parameters on which the quality of vacuum dried product depends the most are the drying temperature, initial thickness of sample, which also implies its relation to the drying time, and the pretreatment applied to it, if any. It is already established that the variety of onion has little effect on colour stability of dried onion (Lewicki et al.,1997. Pretreating the vegetables can decrease the browning during processing and storage, and lower the losses of flavour and of vitamins. Most commonly used pretreating methods adopted for vegetables are sulphiting and dipping into salt $(\mathrm{NaCl})$ solutions. Sulphur is used as a reducing agent that reacts with and traps electrophiles and other intermediates in the Maillard reaction, $\mathrm{NaCl}$ retards oxidative and enzymatic browning, penetrates fast into the tissue, hinders shrinkage and prevents polyphenol oxidase activity (Hawkes and Flink, 1978; Karathanos et al., 1995; Grabowski and Mujumdar, 1992).

Therefore, a study was conducted on quality parameters of vacuum dried onion slices as affected by different operational conditions during drying to offer good quality ready-to-use dehydrated onion to the consumers.

\section{MATERIALS AND METHODS}

Fresh onion (var. Nasik Red) bulbs of almost equal shape and size, without having any physical damage, were purchased from the local market of Kharagpur, India. Thereafter, the onion bulbs were thoroughly cleaned and the scales were peeled off. Onion bulbs were then horizontally cut into slices of required thickness of 1,3 and $5 \mathrm{~mm}$ with a hand operated slicer. The slices were used for two sets of vacuum drying experiments, one without any pretreatment and the other with a pretreatment using a solution of $5 \%$ sodium chloride $(\mathrm{NaCl})$ and $0.2 \%$ potassium metabisulphite $\left(\mathrm{K}_{2} \mathrm{~S}_{2} \mathrm{O}_{5}\right)$ for $15 \mathrm{~min}$ at ambient temperature. The ratio of sliced onion to the pretreatment solution was 1:4 (weight by volume basis). After the specified time, the slices were taken out from the solution and surface moisture was carefully removed by blotting paper.

The drying experiments were conducted in a laboratory scale vacuum dryer consisting of a drying chamber, water tank, electric heater, water pump and a water ring vacuum 
pump. Onion slices were uniformly spread over the aluminium trays in a single layer and the trays were placed over the heated plates, maintained at previously set temperature by hot water circulation through the hollow plates. Water temperature was controlled thermostatically and it was fixed at 50,60 and $70^{\circ} \mathrm{C}$ with $\pm 1{ }^{\circ} \mathrm{C}$ accuracy. Plate temperature was monitored by a thermocouple arrangement. Pressure level inside the drying chamber was maintained at $6.66 \mathrm{kPa}$. The temperature of the heated plates was much higher than the saturation temperature $\left(37.18^{\circ} \mathrm{C}\right)$ of water corresponding to the pressure level maintained inside the chamber, causing boiling of pure water at that temperature. As a consequence, moisture from the product could be easily removed. The product was dried till a constant weight was achieved. After removal of moisture to a level of $3.5 \%$ or less, which was well within the safe limits of $4.5 \%$ or less as per recommendation of ADOGA (2005), Samaniego-Esguerra et al. (1991), the products were taken out of the chamber, cooled in a desiccator and stored in polythene bags. The airtight polythene bags were then shifted to desiccators for further analysis of quality parameters. The series of drying experiments were replicated thrice.

Drying temperature and vacuum level were constant throughout the experiment. The product temperature was measured continuously using a thermocouple arrangement. The weight loss during drying was determined by weighing the trays periodically using an electronic balance (Mettler Toledo, PB3001) of $0.001 \mathrm{~g}$ accuracy. The moisture content, colour (NEB) and flavour (TC) at each interval were determined with the following methods.

Moisture content (MC) is a necessary parameter to predict the quality and shelf life of dehydrated vegetables. MC of fresh and vacuum dried onion slices expressed in dry basis (d.b.), as $\mathrm{kg}$ water $\mathrm{kg}^{-1}$ dry solid was measured by oven drying method (Ranganna, 2005).

Optical index $(O I)$ determination is the most efficient way to measure the extent of browning in dried onion samples. This was done following the official method of ADOGA (2005) which involves the extraction of the brown pigments of the dried onion using $10 \% \mathrm{NaCl}$ solution and measurement of the transmittance of the clear filtrate at $420 \mathrm{~nm}$ by a visible range spectrophotometer (UV-1601, Shimadzu). Transmittance was observed in three replicates and $O I$ was calculated for each sample as a measure of colour in sliced onions.

The pyruvate content or thiosulphinate concentration (TC), which is the resultant product of enzymatic activity of allinase on the flavour precursor ( $S$-alkyl-L-cysteine sulfoxide) in onion, is mainly responsible for flavour intensity or pungency of onion (Fig. 1). A spectrophotometric method was developed to determine thio-sulphinate in dried onion by earlier researchers (Freeman and McBreen, 1973) and later that method was modified (Samaniego-Esguerra et al., 1991) for TC quantification in dried onion (KaymakErtekin and Gedik, 2003). Thiosulphinate was extracted using hexane and absorbance of extracted solution was observed at $254 \mathrm{~nm}$ by UV-VIS spectrophotometer. TC of the solution was calculated using the equation:

$$
T C=A /(\varepsilon b)
$$

where: $A$ is absorbance, $b$ is path length $(\mathrm{cm})$, and $T C$ is the concentration of the solution $\left(\mu \mathrm{mol} \mathrm{g}^{-1}\right), \varepsilon$ is the molar

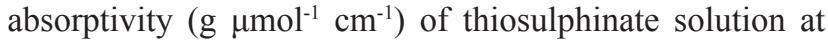

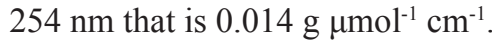

It is desirable to absorb more water during rehydration for a good quality product. The lower the rehydration ratio the better is the rehydration efficiency. Rehydration ratio was determined by using the standard procedure (Ranganna, 2005).

$$
\text { Rehydration ratio }=\frac{\text { sample weight before rehydration }}{\text { sample weight after rehydration }} .
$$

The analysis of variance (ANOVA) test was carried out using data analysis tool pack inbuilt in Microsoft Excel software package (Microsoft corp., Redmond, WA, USA) and statistical procedures were followed to examine the effect of drying temperature and slice thickness on moisture content, colour change, flavour concentration and rehydration characteristics of dried onion slices. Statistical significance was expressed at $\mathrm{p}<0.05$ level.

\section{RESULTS AND DISCUSSION}

In the present study, initial MC of the onion samples was found within the range of 7.37 to 7.20 d.b. It was very difficult to maintain single moisture level initially due to the internal moisture variation of the samples. The final $\mathrm{MC}$ of the dried onion was found within 0.04 to 0.02 d.b. Statistical analysis showed that at $95 \%$ level of significance, not the thickness but the temperature had a significant effect on $\mathrm{MC}$ of untreated onion slices. However, their interaction did not show any significant change. For treated slices, both thickness and temperature had a significant effect. Variation of MC is shown in Fig. 2. For a particular thickness, MC decreased with increasing temperature, as higher temperature caused a higher gradient, thereby effecting moisture removal at a faster rate. The effect of thickness was more pronounced at higher temperature. MC was found to increase slightly with increase in thickness. Sodium chloride and sulphite treatment reduced the final MC to some extent. This may be due to the fact that pretreatment causes softening of the tissue structure, thereby releasing slightly more moisture than the untreated samples.

Initially, at the advent of drying, colour difference was observed between untreated and treated samples due to colour change of treated slices. Initial colours of both untreated and treated samples were measured and it was found more in the case of treated samples. This is due to the absorption/infiltration of sodium chloride in the onion tissues. 

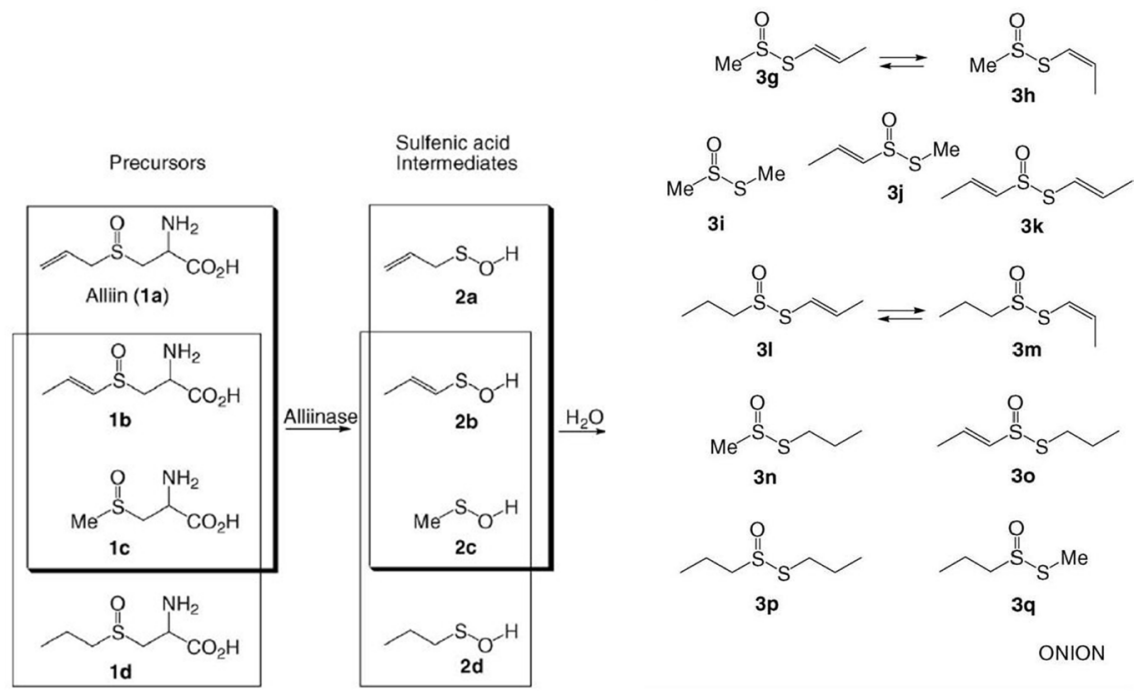

Fig. 1. Biosynthetic pathway of Thiosulphinates in onion (Lanzotti, 2006).

Osmotic treatment imparts a light yellowish colour to the onion slices. This behaviour is also supported by earlier researchers (Bongirwir and Sreenivasan, 1977; Lewicki et al., 1997). However, the difference in optical index (OI) between the final and initial readings indicated that colour change due to NEB was less in treated sample than the untreated one.

Optical index values of onion slices, both initial $\left(O I_{0}\right)$ and after drying $(O I)$, were determined. The difference between the two measurements yielded the colour development due to NEB during drying. The $O I$ values varied from 18.41 to 38.68 for untreated onion slices and from 16.73 to 36.51 for treated slices, which was much less than the $O I$ value reported for convective air dried onion by earlier researchers (Prasad, 1994; Kaymak-Ertekin and Gedik, 2005). However, the maximum $O I$ value for dried onion was reported as 90 (ADOGA, 2005). The main reason for the lower $\mathrm{OI}$ in the case of vacuum drying is due to substantially lower concentration of air as well as oxygen under vacuum conditions. As a result, the colour of dried onion slices was superior in vacuum drying compared to any other conventional drying method.

According to ANOVA, slice thickness and drying tem-

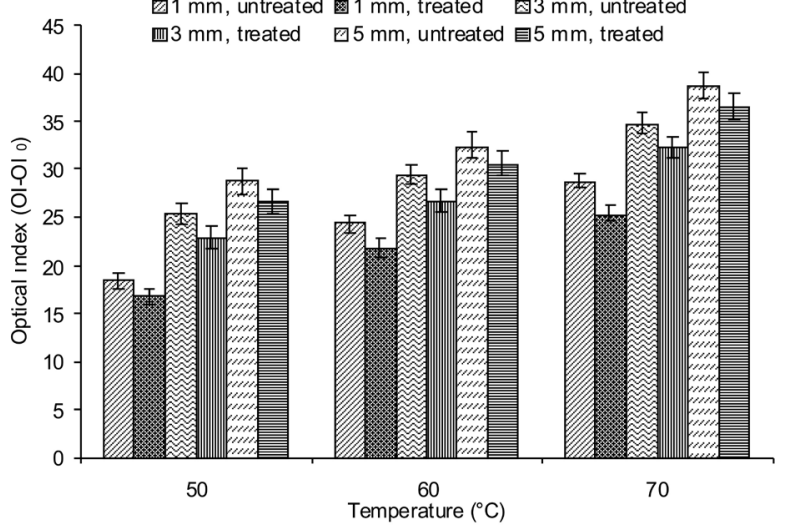

Fig. 3. Non-enzymatic browning represented by $O I-O I_{0}$ of vacuum dried onion slices at different operational conditions. perature both had equally significant $(p<0.05)$ effect on the colour change of dried onion, as also suggested by earlier researchers (Hendel et al., 1955; Labuza and Saltmarch, 1981; Rapusas and Driscoll, 1995; Saguey and Karel, 1980). However, their interaction did not show any significant effect. Colour was also affected by the initial condition of the sample that was treated or the untreated one.

The colour development during drying in terms of change in $O I$ is shown in Fig. 3. From the graph it can be concluded that $O I$ has direct correlation with temperature and slice thickness, which implies its proportional increase with time also. Earlier researchers noticed this increasing nature of $O I$ with time and temperature (Labuza and Saltmarch, 1981; Kaymak-Ertekin and Gedik, 2005; 


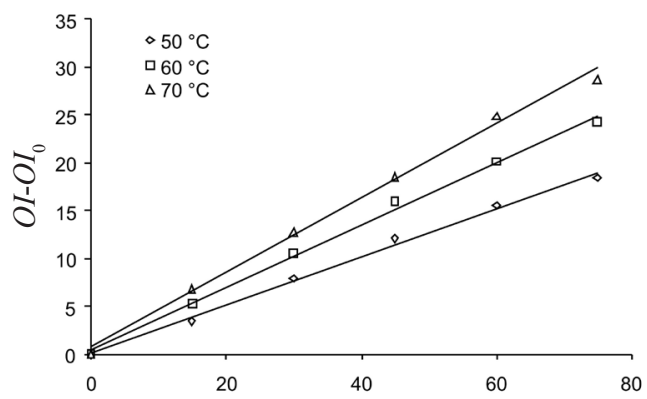

b

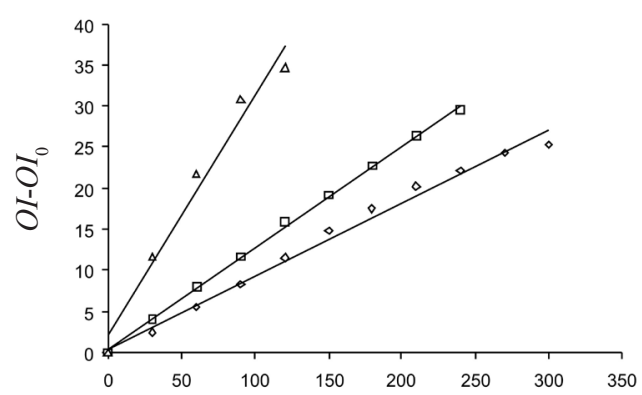

$\mathrm{c}$

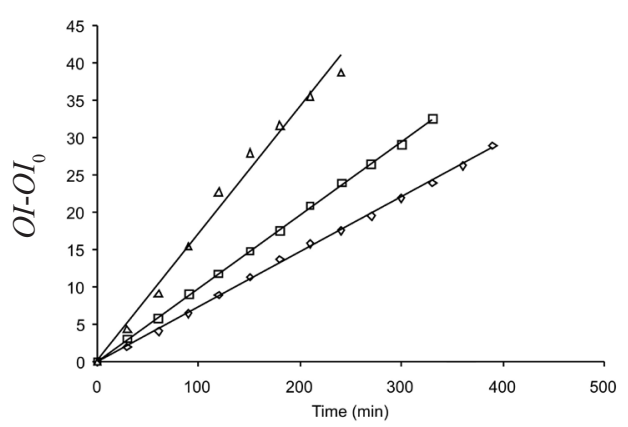

Fig. 4. Non-enzymatic browning represented by $O I-O I_{0} \mathrm{~g}^{-1}$ sample in: $\mathrm{a}-1 \mathrm{~mm}, \mathrm{~b}-3 \mathrm{~mm}, \mathrm{c}-5 \mathrm{~mm}$ thick untreated vacuum dried onion slices at various temperatures.
Rapusas and Driscoll, 1995). Since browning increases with time, it can be easily explained that the thicker samples took more time to dry, causing more browning in onion slices. NEB during vacuum drying of onion followed zero order reaction as stated below:

$$
O I=O I_{0}+k_{c} t
$$

where: $k_{c}$ is the reaction rate constant $\left(\mathrm{min}^{-1}\right)$ for NEB and $t$ is the drying time (min). Zero order reaction for colour change in onion slices was also observed by several researchers during convective drying of onion (KaymakErtekin and Gedik, 2005; Rapusas and Driscoll, 1995). The representative plots are given in Fig. 4. The rate constant $k_{c}$ for all the experimental conditions is listed along with the coefficient of determination $\left(\mathrm{R}^{2}\right)$ in Table 1 . The reaction rate constant for NEB varied from 0.0734 to 0.3878 , showing clear variation due to temperature and thickness. Rate constant increased drastically for higher temperature and decreased for higher thickness. In the case of untreated onion slices, $k_{c}$ values for NEB kinetics were slightly higher than those of treated onion slices. $\mathrm{R}^{2}$ values varied from 0.9742 to 0.9996 . The temperature dependence of $k_{c}$ followed the Arrhenius relationship:

$$
k_{c}=k_{c 0} \exp \left(-E_{a} / R T\right)
$$

where: $k_{c 0}$ is the pre-exponential constant $\left(\mathrm{min}^{-1}\right), E_{a}$ is the activation energy $\left(\mathrm{kJ} \mathrm{mol}^{-1}\right), \mathrm{R}$ is the gas constant $(\mathrm{kJ}$ $\mathrm{mol}^{-1} \mathrm{~K}^{-1}$ ) and $T$ is drying temperature (K). Equation 4 was used for evaluating activation energy for NEB in the case of vacuum drying of onion slices. From the slope of the semi-log plot of $k_{c}$ with inverse of temperature (Fig. 5) the activation energy was calculated. It was clearly shown that the Arrhenius equation fitted reasonably well $\left(\mathrm{R}^{2}>0.92\right)$ to the temperature dependence of rate constants. $E_{a}$ values for NEB were within the range of $19.44-53.76 \mathrm{~kJ} \mathrm{~mol}^{-1}$ for both

\begin{tabular}{|c|c|c|c|c|c|}
\hline \multirow{2}{*}{ Thickness (mm) } & \multirow{2}{*}{ Temperature $\left({ }^{\circ} \mathrm{C}\right)$} & \multicolumn{2}{|c|}{ Untreated sample } & \multicolumn{2}{|c|}{ Treated sample } \\
\hline & & $k_{c}\left(O I \min ^{-1}\right)$ & $\mathrm{R}^{2}$ & $k_{c}\left(O I \mathrm{~min}^{-1}\right)$ & $\mathrm{R}^{2}$ \\
\hline \multirow[t]{3}{*}{1} & 50 & 0.252 & 0.996 & 0.224 & 0.996 \\
\hline & 60 & 0.327 & 0.997 & 0.298 & 0.994 \\
\hline & 70 & 0.388 & 0.995 & 0.346 & 0.991 \\
\hline \multirow[t]{3}{*}{3} & 50 & 0.089 & 0.992 & 0.075 & 0.996 \\
\hline & 60 & 0.123 & 0.999 & 0.116 & 0.998 \\
\hline & 70 & 0.296 & 0.974 & 0.217 & 0.995 \\
\hline \multirow[t]{3}{*}{5} & 50 & 0.073 & 0.999 & 0.074 & 0.993 \\
\hline & 60 & 0.098 & 1.000 & 0.094 & 0.998 \\
\hline & 70 & 0.170 & 0.988 & 0.133 & 0.996 \\
\hline
\end{tabular}

T a b l e 1. Reaction rate constant for NEB kinetics and $R^{2}$ values 


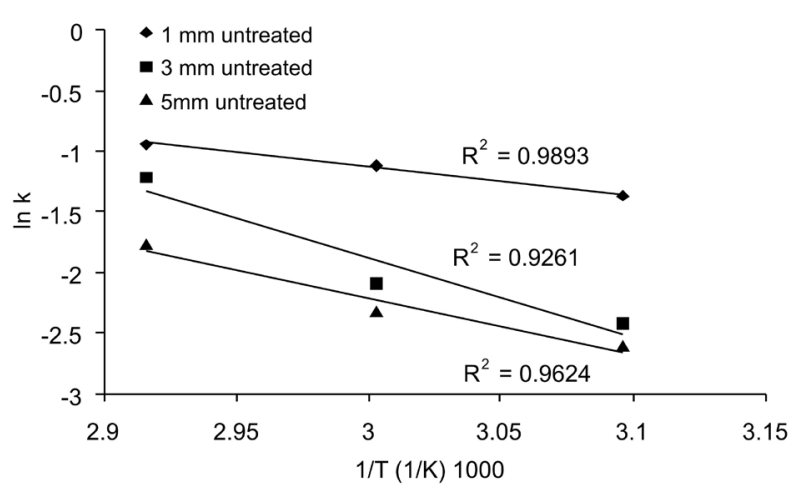

Fig. 5. Arrhenius plot for non-enzymatic browning (NEB) in untreated vacuum dried onion slices.
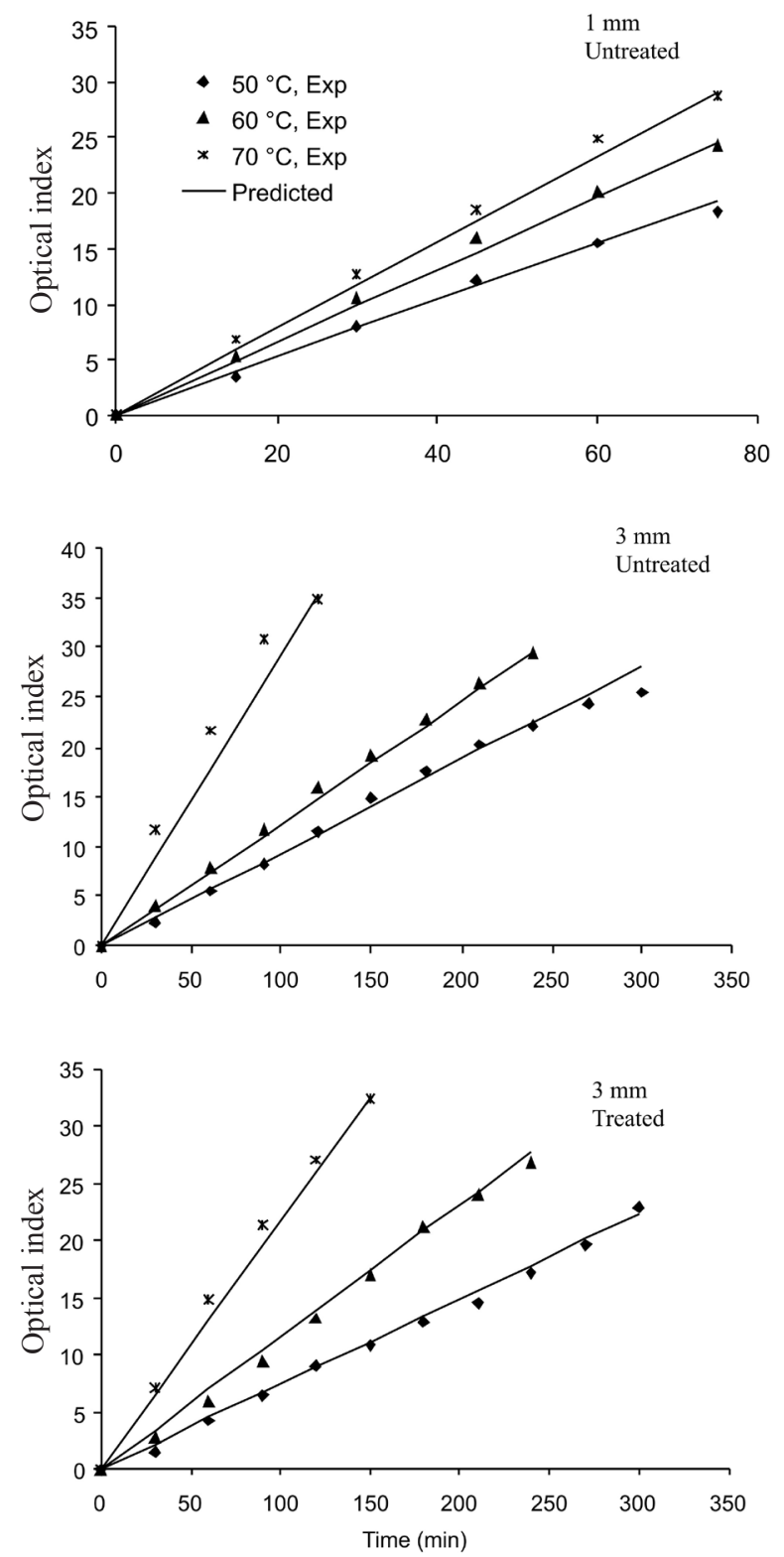

Fig. 6. Actual and predicted optical index $\left(O \mathrm{Ig} \mathrm{g}^{-1}\right.$ sample $)$ for vacuum dried onion slices. treated and untreated samples. These values were higher than the reported range of $E_{a}\left(16.3\right.$ to $\left.27.11 \mathrm{~kJ} \mathrm{~mol}^{-1}\right)$ for browning in the case of hot air dried onion slices (KaymakErtekin and Gedik, 2005), implying that the threshold energy requirement to start NEB is higher in the case of vacuum dried onion, hence, NEB is reduced. Therefore, the combined relation of $O I$ with time and temperature can be achieved as:

$$
O I=O I_{0}+k_{c 0} \exp \left(-E_{a} / R T\right) t
$$

The temperature and time dependence of $O I$ presented in the above equation predicted well the experimental behaviour of colour change in dehydrated onion slices as depicted in Fig. 6. Percentage error (PE) was calculated to analyse the acceptability of the developed equation (Eq. (5)) and is reported in Table 2. The combined equation fitted to the experimental data of NEB in dried onion slices with good accuracy $(\mathrm{PE}<10)$ for almost all of the trials.

Slice thickness, temperature and their interaction had a significant effect $(\mathrm{p}<0.05)$ on flavour content of untreated and treated samples, but the former predominated. The variation of $T C$ with different operational conditions is described in Fig. 6. TC ( $\mu \mathrm{mol} \mathrm{g}^{-1}$ dried sample) increased with increase in slice thickness and decreased with increase in temperature. This phenomenon occurred due to two aspects. Firstly, when onion slices were placed on heated plate, volatile heat sensitive flavour component tried to disappear. Thinner samples exposed a larger surface area, thereby showing a greater loss of volatile components. Secondly, at higher temperatures, though the slices took less time to achieve required final $\mathrm{MC}$, the exposure of the flavour component to higher temperatures caused a lowering of $T C$. The temperature sensitivity of the flavouring component ie pyruvate content of garlic and onions during drying, was reported earlier (Da-Mota and Palau, 1999; Prasad,

T a b I e 2. Percentage error in predicted optical index

\begin{tabular}{|c|c|c|c|}
\hline \multirow{2}{*}{$\begin{array}{l}\text { Thickness } \\
\text { (mm) }\end{array}$} & \multirow{2}{*}{$\begin{array}{c}\text { Temperature } \\
\left({ }^{\circ} \mathrm{C}\right)\end{array}$} & \multicolumn{2}{|c|}{ Percentage error } \\
\hline & & untreated & treated \\
\hline \multirow{3}{*}{1} & 50 & 3.78 & 7.95 \\
\hline & 60 & 3.71 & 5.11 \\
\hline & 70 & 6.24 & 6.15 \\
\hline \multirow{3}{*}{3} & 50 & 4.48 & 7.81 \\
\hline & 60 & 3.79 & 7.30 \\
\hline & 70 & 11.56 & 5.53 \\
\hline \multirow{3}{*}{5} & 50 & 3.05 & 9.79 \\
\hline & 60 & 1.16 & 7.57 \\
\hline & 70 & 6.35 & 4.57 \\
\hline
\end{tabular}




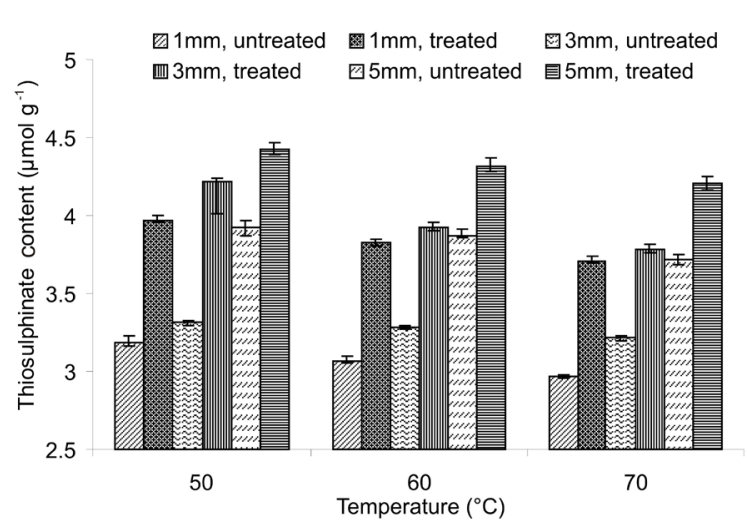

Fig. 7. Thiosulphinate content (TC) of vacuum dried onion slices at different operational conditions.
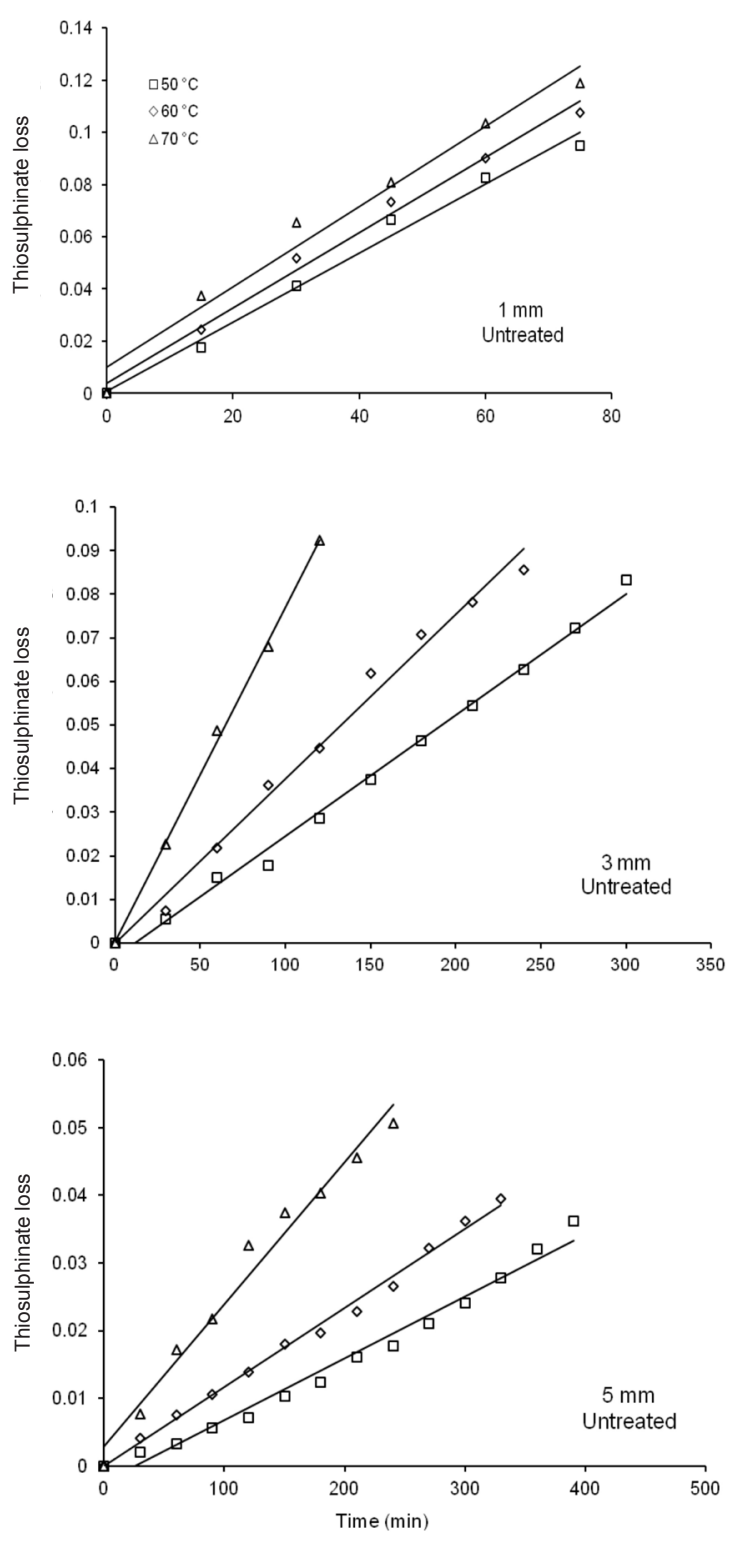

Fig. 8. Thiosulphinate loss $\left(1 / \mathrm{TC}-1 / \mathrm{TC}_{0}\right)$ for untreated vacuum dried onion slices.
1994; Prezzutti and Crapiste, 1997). Initial flavour content in terms of thiosulphinate $\left(T C_{0}\right)$, observed as $4.57 \mu \mathrm{mol} \mathrm{g}^{-1}$, was found to be the same for untreated as well as treated samples. This was well within the range of 3.61-4.97 $\mu \mathrm{mol}$ $\mathrm{g}^{-1}$ based on 20.2 to $10.4 \%$ grade of comminution as reported previously (Resemann et al., 2004). In the case of untreated onion $T C$ was within the range of 2.96-3.92 and 3.71-4.43 $\mu \mathrm{mol} \mathrm{g}{ }^{-1}$ for treated onion. It was evident from the figure that after drying the $T C$ was higher in the case of treated samples compared to the untreated one. Thiosulphinate loss $(T L)$ was determined as the difference between the initial $T C_{0}$ and the final $T C$ after drying. It indicated that flavour loss during the dehydration process was grater in untreated samples, that is the treatment did succeed in controlling the flavour loss during dehydration. Flavour loss increased with increasing temperature, though at a slower rate, and decreased with increasing thickness at a faster rate. Hence, the results proved sulphitation as a potential treatment to retard NEB in dried vegetables and to improve the quality of the final product. The pattern of $T C$ decrease during vacuum drying of onion slices followed a second order model mentioned below:

$$
\frac{1}{T C}=\frac{1}{T C_{0}}+k_{f} t
$$

A relation between $T L$ with drying time at different temperatures was attempted and depicted in Fig. 8 for untreated slices. Similar behaviour was observed for treated slices also. The calculated rate constant $\left(k_{f}\right)$ and $\mathrm{R}^{2}$ values for different operational conditions are listed in Table 3. The reaction rate constant for $T L$ increased with temperature and decreased with slice thickness. The value of $k_{f}$ value ranged from $0.2 \times 10^{4}$ to $15 \times 10^{4} \mathrm{~min}^{-1}$ and temperature effect was significant as also reported by earlier researchers (Kaymak-Ertekin and Gedik, 2005; Prezzutti and Crapiste, 1997). $E_{a}$ was calculated in a way similar to that for NEB kinetics. The representative plot of $E_{a}$ is given in Fig. 9. $E_{a}$ values for thiosulphinate loss were found to be lying between 6.45 and $72.85 \mathrm{~kJ} \mathrm{~mol}^{-1}$ and were in close agreement with $E_{a}$ values reported for $3 \mathrm{~mm}$ thick onion slices ie 47-92 $\mathrm{kJ} \mathrm{mol}^{-1}$. Activation energy was also optimum at $60^{\circ} \mathrm{C}$. The combined model for reaction rate constant of flavour loss and temperature can be attained by replacing $k_{f}$ from Arrhenius type of equation, similar to NEB kinetics, in Eq. (6) and presented as:

$$
\frac{1}{T C}=\frac{1}{T C_{0}}+k_{f 0} \exp \left(-E_{a} / R T\right) t
$$

The ability of the above combined model to predict the $T L$ behaviour for $3 \mathrm{~mm}$ thick untreated and treated onion slices, dried in vacuum environment, are presented in Fig. 10. The PE values are reported in Table 4. Earlier researchers also found comparatively higher $\mathrm{PE}$ values 
T a b l e 3. Reaction rate constant for thiosulphinate loss kinetics and $\mathrm{R}^{2}$ values

\begin{tabular}{|c|c|c|c|c|c|}
\hline \multirow[b]{2}{*}{ Thickness (mm) } & \multirow[b]{2}{*}{ Temperature $\left({ }^{\circ} \mathrm{C}\right)$} & \multicolumn{2}{|c|}{ Untreated sample } & \multicolumn{2}{|c|}{ Treated sample } \\
\hline & & $\begin{array}{c}k_{f} 10^{4} \\
k_{c}\left(O I \min ^{-1}\right)\end{array}$ & $\mathrm{R}^{2}$ & $\begin{array}{c}k_{f} 10^{4} \\
k_{c}\left(O I \min ^{-1}\right)\end{array}$ & $\mathrm{R}^{2}$ \\
\hline \multirow{3}{*}{1} & 50 & 13 & 0.9882 & 5.0 & 0.9666 \\
\hline & 60 & 14 & 0.9903 & 6.0 & 0.9621 \\
\hline & 70 & 15 & 0.9736 & 7.0 & 0.9852 \\
\hline \multirow{3}{*}{3} & 50 & 3.0 & 0.9944 & 0.6 & 0.9803 \\
\hline & 60 & 4.0 & 0.9894 & 2.0 & 0.9877 \\
\hline & 70 & 8.0 & 0.9985 & 3.0 & 0.9809 \\
\hline \multirow{3}{*}{5} & 50 & 0.9 & 0.9820 & 0.2 & 0.9602 \\
\hline & 60 & 1.0 & 0.994 & 0.3 & 0.9663 \\
\hline & 70 & 2.0 & 0.9784 & 0.7 & 0.9760 \\
\hline
\end{tabular}

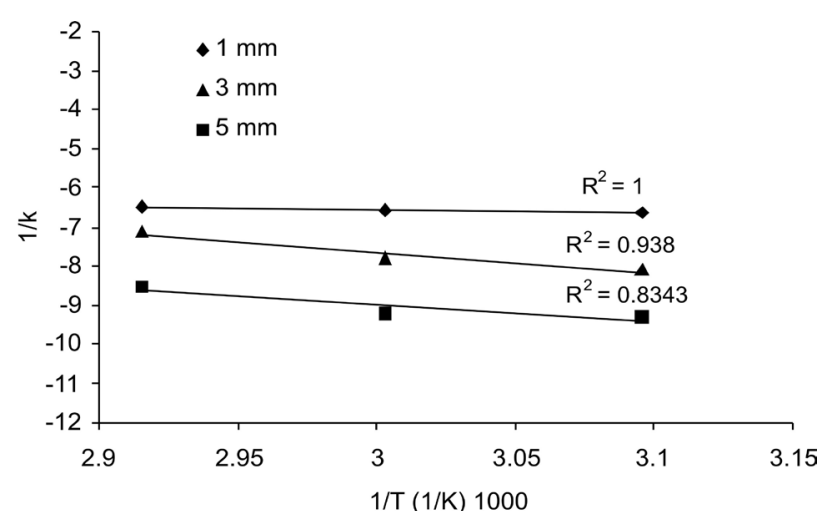

Fig. 9. Arrhenius plot for thiosulphinate content $\left(T C, \mathrm{mmol} \mathrm{g}^{-1}\right.$ sample) in untreated vacuum dried onion slices.

for flavour loss during hot air drying of onion slices, as was found in the present case also (Kaymak-Ertekin and Gedik, 2005).

Statistical analysis showed that both thickness and temperature significantly $(\mathrm{p}<0.05)$ changed the rehydration ratio, but thickness had a more pronounced effect than temperature on the rehydration characteristics of vacuum dried onion slices. However, their interaction did not show any significant change on the final rehydration quality of dried onion slices. The change of rehydration ratio with slice thickness and temperature for untreated and treated samples is presented in Fig. 11. It can be inferred from the graph that rehydration ratio was higher in the case of untreated samples, that is the rehydration efficiency of untreated onion slices was greater than that of treated onion slices. The same behaviour was observed earlier in a research related to rehydration of onion (Debnath et al., 2004). Osmotic pretreatment resulted in a decrease in the diffusion coefficient of water. This may be attributed to an
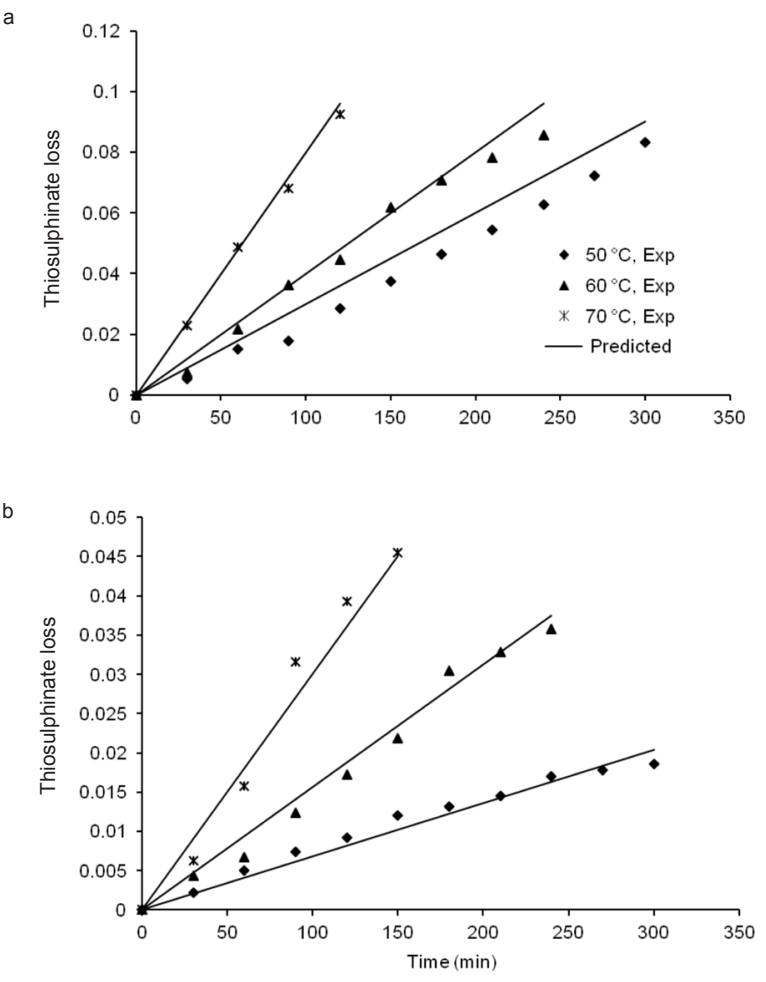

Fig. 10. Actual and predicted thiosulphinate loss $\left(1 / \mathrm{TC}-1 / \mathrm{TC}_{0}\right)$ for: $a-3 \mathrm{~mm}$ untreated, $\mathrm{b}-$ treated onion slices.

increase in the proportion of ruptured and shrunken cells caused by osmotic treatment which in turn reduces the ability of dried onion tissues to absorb water. As temperature increased, the rehydration ratio increased slightly, resulting in a proportional increase in the rehydration efficiency. This is because the faster drying induced less damage to the 
T a b l e 4. Percentage error in predicted flavour loss values

\begin{tabular}{cccc}
\hline \multirow{2}{*}{$\begin{array}{c}\text { Thickness } \\
(\mathrm{mm})\end{array}$} & $\begin{array}{c}\text { Temperature } \\
\left({ }^{\circ} \mathrm{C}\right)\end{array}$ & \multicolumn{2}{c}{ Percentage error } \\
\cline { 3 - 4 } & 50 & 6.16 & 10.64 \\
1 & 60 & 9.35 & 12.57 \\
& 70 & 13.29 & 9.16 \\
& 50 & 14.54 & 8.51 \\
3 & 60 & 17.25 & 10.02 \\
& 70 & 3.37 & 13.49 \\
& 50 & 22.97 & 16.44 \\
& 60 & 14.31 & 17.14 \\
& 70 & 15.60 & 14.28 \\
\hline
\end{tabular}

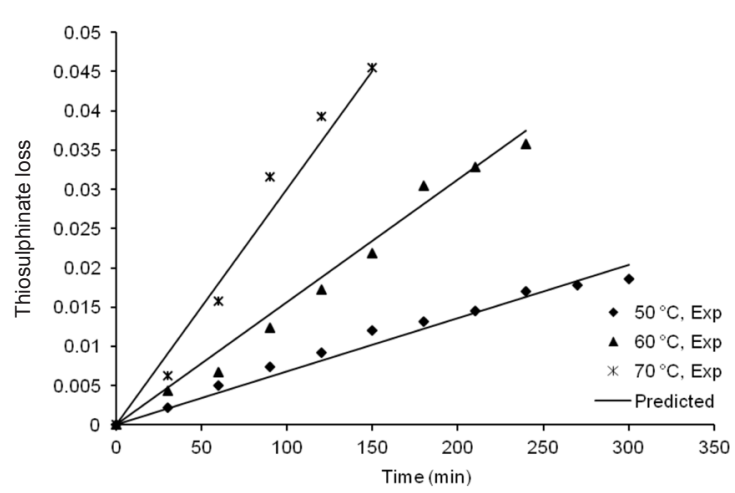

Fig. 11. Rehydration ratio of vacuum dried onion slices at different operational.

cells and, as a consequence, the water absorption efficiency was higher. On the other hand, with increase in thickness, rehydration ratio decreased significantly, thereby reducing rehydration efficiency. Therefore, it can be concluded that along with temperature and thickness, pre-treatment is also a major factor affecting rehydration characteristics.

\section{CONCLUSIONS}

1. This study showed that vacuum drying of onion is an excellent process to preserve onion without significant loss in colour, flavour and rehydration efficiency.

2 . The change in quality parameters in the case of vacuum drying was greatly influenced by drying temperature, thickness and pretreatment.

3. Final moisture content and colour of onion slices were noticeably affected by thicknesses and temperature, whereas in the case of flavour content and rehydration ratio the effect of thickness was predominant.
4. Treated samples were found to be more acceptable than the untreated ones on the basis of colour and flavour characteristics.

5. Because of very low final moisture content and less oxidative damage, vacuum dried onion slices can be preserved for a longer time as compared to conventional dried onions. Chances of contamination of the product are minimised as the whole process takes place in a closed chamber with minimal air.

6. The activation energy values were higher than in conventional drying for non-enzymatic browning kinetics and almost comparable to reported flavour kinetics. Hence, non-enzymatic browning was minimised remarkably.

7. Vacuum drying can be extensively used for drying of onion and reducing the post harvest losses of onion to a great extent by producing a good quality ready-to-use onion slices.

\section{REFERENCES}

Adam E., Mühlbauer W., Esper A., Wolf W., and Spiess W., 2000. Quality changes of onion (Allium cepa $\mathrm{L}$.) as affected by the drying process. Die. Nahrung, 44, 32-37.

Aguilera J.M., Chirife J., Flink J.M., and Karel M., 1975. Computer simulation of non-enzymatic browning during potato dehydration. Lebensmittel-Wissenschaft und Technol., 8, 128-133.

Arslan D. and Özcan M.M., 2010. Study the effect of sun, oven and microwave drying on quality of onion slices. LWT - Fd Sci. Technol., 43(7), 1121-1127.

Bongirwir D.R. and Sreenivasan A., 1977. Studies on osmotic dehydration of bananas. J. Fd. Sci. Technol., 14,104-112.

Cohen E. and Saguy I., 1985. Statistical evaluation of arrhenius model and its applicability in prediction of food quality losses. J. Food Process. Preserv., 9, 273-290.

Copley M.J., Kaufman V.F., and Rasmussen C.L., 1956. Recent development in fruit and vegetable powder technology. Food Technol., 13, 589-594.

Da-Mota V.M. and Palau E., 1999. Acoustic drying of onion. Dry. Technol., 17(4-5), 855-867.

Debnath S., Hemavathy J., Bhat K.K., and Rastogi N.K., 2004. Rehydration characteristics of osmotic pretreated and dried onion. Food Bioprod. Process., 82, 304-310.

Driscoll R.H. and Madamba P.S., 1994. Modelling the browning kinetics of garlic. Food Aus., 46, 66-71.

Drouzas A.E. and Schubert H., 1996. Microwave application in vacuum drying of fruits. J. Food Eng., 28, 203-209.

Freeman G.G. and McBreen F., 1973. A rapid spectrophotometric method of determination of thiosulphinate in onion (Allium cepa) and its significance in flavour studies. Biochem. Soc. Trans., 1, 1150-1152.

Grabowski S. and Mujumdar A.S., 1992. Solar-assisted osmotic dehydration. In: Drying. Elsevier, Amsterdam.

Gyawali R., Seo Hye-Young, Lee Hyun-Ju, Song Hyun-Pa, Kim Dong-Ho, Byun Myung-Woo, and Kim Kyong-Su, 2006. Effect of $\gamma$-irradiation on volatile compounds of dried Welsh onion (Allium fistulosum L.). Radiation Physics Chemistry, 75(2), 322-328. 
Hawkes J. and Flink J.M., 1978. Osmotic concentration of fruit slices prior to freeze dehydration. J. Food Process Eng., 2, 265-284.

Hendel C.E., Silveira V.G., and Harrington W.D., 1955. Rates of nonenzymatic browning of white potato during dehydration. J. Food Technol., 9, 433-438.

Ibarz A., Pagan J., and Garza S., 2000. Kinetic models of nonenzymatic browning in apple puree. J. Sci. Food Agric., 80, 1162-1168.

Jena S. and Das H., 2007. Modelling for vacuum drying characteristics of coconut press cake. J. Food Eng., 79, 92-99.

Karathanos V.T., Karanikolas T., Kostaropoulos A.E., and Saravacos G.D., 1995. Non enzymatic browning in airdrying of washed raisins. Dev. Food Sci., 37(1), 1057-1064.

Kaymak-Ertekin F. and Gedik A., 2005. Kinetic modeling of quality deterioration in onions during drying and storage. J. Food Eng., 68, 443-453.

Krokida M.K. and Maroulis Z.B., 1999. Effect of microwave drying on some quality properties of dehydrated products. Dry. Technol., 17(3), 449-466.

Kumar Praveen D.G., Hebbar Umesh H., and Ramesh M.N., 2006. Suitability of thin layer models for infrared-hot airdrying of onion slices. LWT - Fd Sci Technol., 39(6), 700-705.

Labuza T.P., 1973. Effects of dehydration and storage. Food Technol., 27, 20-26.

Labuza T.P. and Saltmarch M., 1981. The non enzymatic browning reaction as affected by water in foods. In: Water Activity: Influences on food Quality (Eds L.B. Rockland, G.F. Stewart). Academic Press, New York, USA.

Lanzotti V., 2006. The analysis of onion and garlic. J. Chromatogr., A., 1112 (1-2), 3-22.

Legault R.R., Hendel C.E., and Talburt W.F., 1954. Retention of quality in dehydrated vegetables through in-package dessication. Food Technol., 8, 143-149.

Lenz M.K. and Lund D.B., 1980. Experimental procedures for determining destruction kinetics of food components. Food Technol., 34, 51-55.

Lewicki P.P., Pomaranska-Lazuka W., Witrowa-Rajchert D., and Nowak D., 1997. Storage stability of dried onion. Part I. Colour. J. Food Qual., 22, 505-516.

Mazza G. and LeMaguer M., 1980. Flavour retention during dehydration of onion. In: Food Process Engineering (Eds P. Linko, Y. Malkki, J. Olkku, J. Larinkari). Applied Sci. Press, Ltd. London, UK.

Mota C.L., Luciano C., Dias A., Barroca M.J., and Guiné R.P.F., 2010. Convective drying of onion: Kinetics and nutritional evaluation. Food Bioprod. Proc., 88(2-3), 115-123.

Official standards and methods of the American dehydrated onion and garlic Association for the dehydrated onion and garlic products, 2005. Technical committee of ADOGA, San Francisco, CA, USA.
Panse V.G. and Sukhatme P.V., 1967. Statistical methods for agricultural workers. Second Edition. ICAR publication, New Delhi, India.

Pap L., 1995. Production of pure vegetable juice powders of full biological value. Fruit Process., 3, 55-60.

Peleg Y., Mannheim C.H., and Berk Z., 1970. Changes in quality of dehydrated kibbled onions during storage. J. Food Sci., 35, 513-517.

Péré C. and Rodier E., 2002. Microwave vacuum drying of porous media: experimental study and qualitative considerations of internal transfers. Chem. Eng. Proc., 41, 427-436.

Prasad B.V.S., 1994. Studies on dehydration of onion and ginger. Ph.D. Thesis, Indian Institute of Technology, Kharagpur, India.

Prezzutti A. and Crapiste G.H., 1997. Sorptional equilibrium and drying characteristics of garlic. J. Food Eng., 31, 113-12.

Proudlove R.K., 1989. The science and technology of foods. Forbes Publications Ltd., London, UK.

Ranganna S., 2005. Hand Book of Analysis and Quality Control For Fruits and Vegetable Products. Tata McGraw Hill Book Press, New Delhi, India.

Rapusas R.S. and Driscoll R.H., 1995. Thermophysical properties of fresh and dried white onion slices. J. Food Eng., 24, 149-164

Resemann J., Maier B., and Carle R., 2004. Investigations on the conversion of onion aroma precursors S-alk(en)yl-Lcysteine sulphoxides in onion juice production. J. Sci. Food Agric., 84, 1945-1950.

Saguey I. and Karel M., 1980. Modelling of quality deterioration during food processing and storage. Food Technol., 34, 78-85.

Samaniego-Esguerra C.M., Boag I.F., and Robertson G.L., 1991. Kinetics of quality deterioration in dried onions and green beans as a function of temperature and water activity. Lebensm. Wiss. U. Technol., 24, 53-58.

Sarsavadia P.N., Sawhney R.L., Pangavhane D.R., and Singh S.P., 1999. Drying behaviour of brined onion slices. J. Food Eng., 40, 219-226.

Schwimmer S., 1981. Source book of food enzymology. AVI Press, Westport, CT, USA.

Schwimmer S. and Weston W.J., 1961. Enzymatic development of pyruvic acid in onion as a measure of pungency. J. Agric. Food Chem., 9, 301-304.

Vega-Gálvez A., Lemus-Mondaca R., Bilbao-Sáinz C., Fito P., and Andrés A., 2008. Effect of air drying temperature on the quality of rehydrated dried red bell pepper (var. Lamuyo). J. Food Eng., 85, 42-50.

Virginia L., 2006. The analysis of onion and garlic. J. Chrom., 1112(1-2), 3-22.

Wang J. and Chao Y., 2003. Effect of ${ }^{60} \mathrm{Co}$ irradiation on drying characteristics of apple. J. Food Eng., 56, 347-351. 